\title{
Ethnicity and religiosity-based prejudice in Turkey: Evidence from a survey experiment
}

S. Erdem Aytaç (corresponding author)

Assistant Professor, Koç University

saytac@ku.edu.tr

Ali Çarkoğlu

Professor, Koç University

acarkoglu@ku.edu.tr

\section{This is a pre-copy edited version. Cite as:}

Aytaç, S. Erdem and Ali Çarkoğlu. 2017. "Ethnicity and Religiosity-based Prejudice in Turkey: Evidence from a Survey Experiment." International Political Science Review. Published online June 12. https://doi.org/10.1177/0192512117696333

\begin{abstract}
Threat perceptions and prejudice underlie a large number of intergroup conflicts. In this article we explore prejudicial attitudes in Turkey regarding ethnic Kurdish and devout Muslim religious identities as opposed to Turkish and less observant/secular identities. Utilizing a populationbased survey experiment, we use vignettes about a hypothetical family as a neighbour, with randomized ethnicity- and religiosity-related cues. We find evidence for prejudice against Kurdish ethnicity, especially among older, lowly-educated and economically dissatisfied individuals. The level of prejudice against Kurds does not seem to be related to the relative size of the Kurdish population in the local population. We do not observe prejudice against devout Muslim or less observant, secular identities. Our findings indicate that prejudice against Kurds in Turkey does not have a sui generis nature. The lack of prejudice across the religiosity dimension suggests that major socio-political cleavages do not necessarily affect intergroup attitudes.
\end{abstract}

\section{Keywords}

Prejudice, ethnicity, religiosity, survey experiment, Kurds, Turkey. 
Prejudicial attitudes have far-reaching social and political consequences. Research has shown that prejudice against out-groups, defined as 'antipathy accompanied by a faulty generalization' (Pettigrew, 1980: 821), underlie a large number of intergroup conflicts, affects individuals' evaluations of candidates to office, their levels of political participation, and attitudes towards various policies including immigration, welfare provision, and affirmative action. ${ }^{1}$ It is rather difficult to explain the rise of extreme right-wing and populist politicians without taking into account high levels of prejudice among their supporters against some out-groups in society. Therefore, it is imperative to study different reflections of prejudicial attitudes in different contexts to better understand the sources and dynamics of such attitudes.

A potential manifestation of prejudice against out-groups is residential segregation, i.e., the degree to which different groups live separately in different parts of the urban environment (Massey and Denton, 1988). As individuals feel 'disturbed' by neighbours with specific characteristics, be it race, ethnicity, or religiosity, and prefer to live in neighbourhoods with certain types of people, a process of self-selection into specific neighbourhoods and pushing out of out-groups is initiated (Bobo and Zubrinsky, 1996; Bishop, 2008). In the context of racial residential segregation in the US, it has been shown that the subsequent homogenization of communities results in the concentration of poverty and crime in certain neighbourhoods and deterioration of public services. This leads to further reduction in the social mobility of disadvantaged groups and heighted tension and conflict between different groups (Charles, 2003).

In this article we study the prevalence and determinants of prejudice in the socio-political context of Turkey using an experimental research design. The Turkish political landscape has long been dominated by two major cleavages across the dimensions of ethnicity and religiosity, 
and the Turkish state has continuously been challenged by ethnic separatist and Islamist movements (Aktürk, 2015). While the ethnic cleavage revolves around the relationship between the Turkish majority and the sizeable Kurdish minority, a second source of tension is between devout Muslims and less observant, secular groups. ${ }^{2}$ Is it possible to observe reflections of these cleavages in the form of prejudice against members of the respective groups? If such prejudice exists, what are its drivers? To date, most studies of prejudice have focused on race relations in the US or on attitudes towards immigrants in Western democracies. Through consideration of the Turkish case we expand knowledge of prejudice by providing new insights into its dynamics in a developing, unconsolidated democracy.

While we are the first to analyse prejudice across religiosity in Turkey using nationally representative survey data to the best of our knowledge, there is a nascent literature focusing on inter-ethnic relations. Yet these studies have relied on observational data from samples drawn from the general population (e.g., Dixon and Ergin, 2010; Sarıgil and Karakoç, 2016) and from college students (Bilali, 2014; Çelebi et al., 2014; 2016), or on ethnographic accounts (e.g., Saraçoğlu, 2009). As such, although these studies have surely contributed to our understanding of inter-ethnic prejudice, they have certain limitations. While cross-sections of observational data cannot eliminate confounding factors that may be responsible for the observed differences in prejudice and other beliefs and attitudes, results from samples of college students and ethnographic studies raise concerns of generalizability.

We address these limitations by presenting data from a vignette experiment embedded in a nationally representative household survey in Turkey. This design allows us to draw stronger causal inferences about ethnicity- and religiosity-based prejudice. We operationalize prejudice via our respondents' expressions of disturbance by a hypothetical new neighbour with certain 
characteristics. Specifically, we utilize short vignettes about the hypothetical situation of a new family moving in next to the respondent's apartment/house with randomized manipulations in the description of the family across the dimensions of ethnicity and religiosity. We then examine whether respondents in different experimental treatment groups are more or less likely to report disturbance by the new neighbour. This set-up should alleviate concerns about endogeneity and omitted variable bias when making causal claims.

Our experimental results point to the presence of prejudice against Kurdish ethnicity, especially among older, lowly-educated and economically dissatisfied individuals. The level of prejudice against Kurdish ethnicity does not seem to be related to the relative size of the Kurdish population living in the respondent's local population. Hence we do not find evidence in favour of group-level theories of prejudice such as 'group-threat' (Blalock, 1957; 1967) or 'intergroupcontact' (Allport, 1954) hypotheses. We do not observe prejudice against devout Muslim or less observant, secular identities, suggesting that at the individual level there is a lack of attitudinal reflection of a major socio-political cleavage in Turkish society, at least as conceptualized and measured as in our research design.

\section{Background on the Turkish context}

Şerif Mardin (1973) has provided an explanatory framework for the socio-historical dynamics that shape modern Turkish politics - the ethnic and religious vs. secular cleavages that underlie the major tensions during the Republican era. The core argument of Mardin is that a historical divide stemming from the Ottoman Empire was inherited by the Republican regime after 1923. This divide consisted of a deeply entrenched cultural division between the antagonistic, parochial and traditionalist 'peripheral' forces and the ruling elites of the 'centre' and its societal coalition partners who remained dominant in the Turco-Ottoman polity. This 
social cleavage was primarily a cultural one, differentiating the ruling elites of the centre from the subjects of the periphery. The ruling centre always had a self-ascribed superiority over the subject peripheral masses in cultural terms. They also effectively 'owned' the state and its political apparatus. In the modern day, the quasi-autonomous bureaucracy, especially of the security circles, together with various layers of mostly state-dependent businesses and the various branches of the intellectual community and academia are all integral parts of the centre. During the Republican era the centre adopted a top-down modernization program that alienated the peripheral masses. As such, the centre has come to be associated with values that remained foreign to the peripheral masses.

Mardin posits that the nature of the centre and its relations with the periphery remained more or less unchanged during the Republican period. This subtle continuity is underlined by a deep suspicion on both sides of the cleavage. Up until quite recently, when the pro-Islamist peripheral Justice and Development Party (Adalet ve Kalknnma Partisi, AKP) came to power, the periphery remained a mix of ethnic and linguistic as well as religious groups that were systematically kept out of the ruling circles. Such exclusion bound these groups in their rebellious opposition to the centre. Since these groups were the source of defiant opposition to the new regime and its modernization reforms in the early decades of the Republic, and responsible for a series of bloody rebellions, they are at the root of Republican fears and sensitivities concerning the regime's survival in the longer run.

If a cleavage along the lines described by the centre-periphery framework were effective in Turkish politics, one would expect the centre and the periphery to display divergent cultural characteristics. Hence, instead of a class divide based on economic cleavages, differences on the basis of value systems and world visions should divide politically salient constituencies. The 
centre has relied on the support of groups with relatively lower levels of religiosity, lower concentration of ethnic minorities as well as a more urban presence. In contrast, the peripheral constituencies comprise of more religious, rural and lowly-educated groups with a significant presence of ethnic minorities. Thus, the major socio-political tensions in Turkey are expected to correspond to dichotomies between relatively less religious, secular groups and devout Muslims as well as between Turkish and different ethnic, mainly Kurdish, groups. ${ }^{3}$

Despite these assertions of major socio-political tensions in Turkey, the attitudinal and behavioural implications across different social groups remain largely unexplored. Recently, however, we observe a burgeoning literature on the inter-ethnic relations between Turks and Kurds. Dixon and Ergin (2010) and Sarıil and Karakoç (2016) analyse attitudes towards Kurds in Turkey using data from national samples. Dixon and Ergin (2010) report that secular and nationalist Turks are more likely to think that Kurds have a 'bad influence on the way things are going in Turkey'. Sarıgil and Karakoç (2016) employ several measures of inter-ethnic tolerance between Turks and Kurds, and find that while religiosity, income level, economic satisfaction, and having social contact with Kurds are positively associated with Turks' social tolerance towards Kurds, having ethno-nationalist orientations has a negative impact.

As mentioned earlier, such inferences are subject to the presence of confounding factors, and isolating the causal effect on attitudes is problematic due to concerns about endogeneity and omitted variable bias. Consider the finding in Sarıgil and Karakoç (2016: 13) that 'having private contacts with out-group members...increases the likelihood of Turks' social tolerance towards Kurds'. It is certainly possible that the direction of effect goes not from having private contacts to greater social tolerance but the other way around, or a third factor might be responsible for both having private contacts and greater social tolerance. ${ }^{4}$ Similarly, having ethno-nationalist 
orientations (e.g., voting for a Turkish nationalist party) might be just an indicator of holding prejudicial views about Kurds rather than being an explanatory factor itself.

In another strand of research focusing on the social psychology of the Kurdish conflict in Turkey, stronger ethnic identification among both Turks and Kurds is found to be negatively associated with out-group trust (Çelebi et al., 2014) and positively associated with a heightened perception of ethnic tensions in the society (Bilali, 2014). Higher national identification among Turks is associated with lower support of Kurdish rights while contact with Kurds has a positive effect (Çelebi et al., 2016). In addition to issues of causality due to the observational nature of the data, the samples used in these studies are drawn exclusively from college students, and hence we do not know whether the reported results are generalizable to the broader Turkish population. Finally, employing a different research design, Saraçoğlu (2009) conducts ninety indepth interviews in a major Western Turkish city and reports significant prejudice against Kurdish migrants as well as high levels of urban ethnic segregation. The question of generalizability of the reported results applies to this study as well, and the research design does not allow us to systematically analyse the drivers of the reported prejudice.

In the following we develop an experimental research design with these considerations in mind, and focus on a specific reflection of prejudice, namely the degree of disturbance one feels with having individuals as neighbours not only with different ethnicity but also with different levels of religiosity. The degree of disturbance individuals report with respect to having neighbours with certain characteristics is frequently employed to measure the degree of prejudice against out-groups in a society. The World Values Survey (WVS, www.worldvaluessurvey.org), for example, presents a list of various groups of people that could be seen as out-groups (e.g., people of a different race or religion, immigrants, homosexuals, people speaking a different 
language) and asks whether the respondent would not like to have as neighbour someone from any of these groups. In the sixth wave of the survey (2010-2014) this question was asked to respondents in 60 countries including Turkey. The average proportion of respondents reporting to prefer not to have someone as neighbour from the groups listed was about $60 \%$ in Turkey, a quite high figure compared to the average of the other countries participating in the survey (about 38\%). The WVS questions, however, do not tap into the ethnicity and religiosity cleavage that we observe in the Turkish context; therefore we do not know whether there are similarly high levels of ethnicity- and religiosity-based prejudice in Turkey. Our research also speaks to this question using an experimental design.

\section{Research design}

We embedded a survey experiment into a nationally representative face-to-face survey fielded in Turkey between 2 February and 7 April $2013(N=1,620) .{ }^{5}$ Some descriptive statistics of the sample are presented in Table 1. Population-based survey experiments such as ours have the unique advantage of simultaneously addressing concerns of internal validity and generalizability to a defined target population (Mutz, 2011). Respondents in our survey were randomly assigned to one of the four different versions of the questionnaire. ${ }^{6}$ In each version a short vignette about the hypothetical situation of a new family moving in next to the respondent's apartment or house was presented. The outcome question asked how disturbed, if at all, the respondent would feel by the moving in of the new family.

[TABLE 1 ABOUT HERE] 
Our manipulations consisted of changing the description of the family in question across the dimensions of ethnicity and religiosity. Two versions of the vignette included information suggesting that the family was of Kurdish ethnicity. Specifically, we emphasized that the family used to live in Hakkari - a city in Southeastern Turkey well known to have a predominantly Kurdish population - and that they could speak Kurdish. The remaining two versions included similar information pointing at Turkish ethnicity - that the family used to live in a city with a predominantly Turkish population and that they could not speak any language other than Turkish.

On the religiosity dimension, two versions of the vignettes highlighted that the couple was very observant of religious practices, and that the mother of the family was a housewife covering her head in line with Islamic conservative principles (tesettürlü). ${ }^{7}$ In the remaining two versions we pointed out that the couple was not that observant of religious practices and that the mother of the family was a working woman not covering her head. In the Turkish context religiosity is negatively correlated with married women's employment. Among the married female respondents in our sample, only $5 \%$ of those who pray more than once a week were employed. This figure is almost three times higher (14\%) for the remaining married female respondents. Similarly, only 7\% of married male respondents in our sample who pray more than once a week stated that their spouses were working compared to $17 \%$ for the remaining married male respondents. Thus mentioning the employment status of the mother of the family emphasizes the religious or less observant, secular identity of the family in a rather subtle way in the Turkish context.

This set-up corresponds to a 2 X 2 between-subjects design with four experimental groups that we label as Kurdish-Secular, Kurdish-Religious, Turkish-Secular, and Turkish- 
Religious (Table 2). The exact wording of the vignettes is presented below, with parts of manipulations highlighted in capital letters.

Let's assume that a new family moves in to the vacant apartment/house next to yours. $\mathrm{Mr}$ Mehmet, who is the head of a family who used to live in [HAKKARI / SINOP], is about 35-40 years old with regular income. Mr Mehmet's wife, Mrs Ayşe, is a [WORKING WOMAN NOT COVERING HER HEAD / HOUSEWIFE COVERING HER HEAD (TESETTÜRLÜ)] about 2530 years of age.

Mr Mehmet and Mrs Ayşe are [NOT THAT OBSERVANT OF RELIGIOUS PRACTICES / VERY OBSERVANT OF RELIGIOUS PRACTICES]. In addition, they [SOMETIMES SPEAK KURDISH WITH THEIR CHILDREN AND AMONG THEMSELVES / DO NOT SPEAK ANY LANGUAGE OTHER THAN TURKISH].

\section{[TABLE 2 ABOUT HERE]}

Our outcome question for all versions is the same and reads as: 'Could you tell me how disturbed you would feel, if at all, if Mr Mehmet and his family became your neighbour on a scale from 0 to 10 where 0 indicates 'none at all' and 10 indicates 'I would feel very disturbed'?'

At this point we should highlight that our results are likely to underreport the levels of ethnicity- and religiosity-based prejudice in Turkish society due to the potential presence of social desirability bias in respondents' answers. Social desirability bias refers to the observation that survey items that directly ask about sensitive subjects such as racial attitudes or sexual behaviour may lead individuals to give answers that conform to social norms (Bradburn et al., 1978). While we have couched our measure of prejudice in the context of a hypothetical neighbour, if some respondents perceived our ethnicity and religiosity stimuli to be too explicit and also felt uncomfortable reporting disturbance due to the hypothetical neighbour's ethnicity or religiosity, then they might have chosen to underreport their true level of disturbance. ${ }^{8}$ In this case the magnitude of the reported prejudice would be lower than its actual value, though it 
should still be possible to have inference on the correlates of such prejudice, which we explore next.

\section{Results}

Figure 1 shows the mean disturbance levels for the different experimental groups in the overall sample. Three observations stand out. First, we see that the mean levels of disturbance are quite low around 2 in the $0-10$ scale. As such, the overall levels of tension across the groups posited in our experimental treatments appear to be not very intense. ${ }^{9}$ The potential existence of social desirability bias associated with our explicit measure of prejudice might have played a role in this result. Even in this case, however, we see that the ethnicity dimension of our experiment did lead to different levels of disturbance: The mean levels of disturbance for the Kurdish-Secular and Turkish-Secular treatments are 2.19 and 1.52 , respectively, and the difference is statistically significant $(p<0.001)$. Similarly, the difference between the mean levels of disturbance for the Kurdish-Religious (2.13) and Turkish-Religious (1.57) treatments is statistically significant as well $(p<0.01)$. In contrast, the secular vs. religious dimension does not lead to statistically significant differences in the mean levels of disturbance, both for the Kurdish and Turkish treatments.

\section{[FIGURE 1 ABOUT HERE]}

Accordingly, having a Kurdish neighbour is considered to be more disturbing than having a Turkish one among the respondents in our sample. This result holds regardless of the religiosity level of the hypothetical neighbour. Our findings are robust in regression analyses in which the 
experimental treatments are included as independent variables with and without covariates of gender, age, education, and whether the respondent speaks Kurdish (Table 3).

\section{[TABLE 3 ABOUT HERE]}

\section{Factors accounting for prejudice}

Which sub-groups of the population are more likely to be disturbed by having a Kurdish family as neighbour? In order to answer this question, we pool together the two treatment groups that involve a Kurdish family moving in (i.e., Kurdish-Secular and Kurdish-Religious) into a single treatment group, Kurdish Treatment, and the remaining two groups that involve a Turkish family are pooled together as well. We set aside the respondents in our sample who speak Kurdish (our proxy for Kurdish ethnicity) and look for the effects of variables that are considered in the literature as predictors of prejudice against ethnic out-groups (Schuman, 1997; Krysan, 2000). ${ }^{10}$

In particular, we examine the interactions of our Kurdish-ethnicity treatment with a respondent's gender, age, level of education, self-perceived position in the society, satisfaction with his or her economic condition, and the Kurdish proportion of the population of the district where he or she lives. Our measure of self-perceived position in the society is based on the question 'Some people have a high status in society while others have a low status. Where would you place yourself on a ladder of social status where 1 corresponds to the lowest social status and 10 to the highest?' We also asked respondents to rate their satisfaction with their current economic condition in a scale from 0 (not satisfied at all) to 10 (very satisfied).

Table 4 presents the results of our analysis. In Model 1, we regress the dependent variable (level of disturbance by the neighbour moving in) on the Kurdish-ethnicity treatment 
indicator (Kurdish Treatment), our individual-level predictors, and their interactions with the Kurdish-ethnicity treatment (as indicated by Interaction with treatment variables). The coefficients of the stand-alone constituent terms indicate the variables' effects on the respondents' disturbance by the Turkish-ethnicity treatment, and the coefficients of the interaction terms indicate the variables' effects in the case of the Kurdish-ethnicity treatment. Hence we focus on the interaction terms to analyse which factors are related to prejudice against a Kurdish neighbour.

\section{[TABLE 4 ABOUT HERE]}

We find evidence that while age is positively related to prejudice against a Kurdish neighbour, individuals with higher levels of education and economic satisfaction show less prejudice, as indicated by the statistically significant coefficients of the interactions of these variables with the Kurdish treatment indicator. These results are consistent with the findings in the literature. The negative relationship between formal education and ethnic prejudice is considered 'one of the most consistent findings in social research on ethnic attitudes' (Coenders and Scheepers, 2003). Studies have also shown that older cohorts generally are more prejudiced than younger cohorts (e.g., Firebaugh and Davis, 1988; Schuman, 1997). The link between economic dissatisfaction and ethnic prejudice is thought to operate through frustration: Individuals frustrated by their economic hardships are more likely to project their frustrations and insecurity in the form of prejudice against ethnic out-groups (Quillian, 1995; Burns and Gimpel, 2000); our results are consistent with this interpretation as well. In contrast, we do not find any effects of gender or self-perceived position in the society on prejudice against Kurds in Turkey. 
For expository purposes, Figure 2 displays the mean levels of disturbance across the experimental groups for respondents with primary education only (about $49 \%$ of the sample, leftpanel) and for respondents with beyond-primary-level education (right-panel). For respondents with beyond-primary-level education, the mean levels of disturbance across the groups are very close to each other. In contrast, respondents with only a primary education are significantly more disturbed by a Kurdish family than a Turkish one. This pattern holds regardless of whether the family moving-in is secular or religious. The secular vs. religious dimension does not lead to significantly different levels of disturbance in either group.

\section{[FIGURE 2 ABOUT HERE]}

Similarly, in Figure 3 we divide our respondents into two groups based on their satisfaction with their current economic condition: respondents who rated their satisfaction above five in a $0-10$ scale are labelled as 'economically satisfied' (about $37 \%$ of the sample) while others are considered as 'economically dissatisfied.' The mean levels of disturbance across the experimental groups for economically dissatisfied respondents are presented in the left-panel and for economically satisfied respondents in the right-panel. Again we see that the secular vs. religious dimension does not lead to significantly different levels of disturbance in either group. In contrast, dissatisfaction with one's own economic condition seems to lead to more prejudice against Kurds: Economically dissatisfied respondents are significantly more disturbed by a Kurdish neighbour than a Turkish one while no such effect is discerned among economically satisfied respondents.

[FIGURE 3 ABOUT HERE] 
So far we have considered individual-level predictors of prejudice against out-groups. An important group-level factor that is thought to shape prejudice against out-groups is the size of the minority group relative to that of the majority group in the local population. There are two contrasting accounts about how the relative size of the minority group might shape the majority group's prejudice. The first perspective, the 'group-threat' hypothesis, holds that prejudice of the majority group is heightened as the relative size of the minority group increases in the local population (Blalock, 1957; 1967). The proposed mechanisms for this effect are increased competition for scarce resources and greater potential for the minority group's political mobilization, leading to greater threat perception and prejudice by the majority group. In contrast, the 'intergroup-contact' hypothesis predicts reduced prejudice as a result of greater minority group population because of increased opportunities for contact and communication between the groups (Allport, 1954). In this view contacts with the members of out-groups should lead to more favourable attitudes and reduced prejudice.

There is empirical support in the literature for both of these hypotheses. For instance, Quillian (1995) reports that the level of anti-immigrant prejudice in 12 European countries is positively correlated with the size of the immigrant group. In the US, anti-black prejudice among whites is higher in localities with a higher black population (Taylor, 1998). On the other hand, Wagner et al. (2003) link consistently higher levels of prejudice against foreigners in East Germany to substantially lower presence of foreigners there compared to West Germany, leading to fewer opportunities for intergroup contact. Hood and Morris (1998) find that AngloAmericans living in heavily Hispanic or Asian localities are more favourable towards these groups; a similar result is reported by Dixon and Rosenbaum (2004). A meta-analysis of more 
than 500 studies concludes that intergroup contact typically reduces intergroup prejudice (Pettigrew and Tropp, 2006).

In order to explore whether there is support for either of these hypotheses in our case, we included a variable estimating the Kurdish proportion of the population of the district where the respondent lives, Kurdish Population, and its interaction with the Kurdish-ethnicity treatment indicator into our specification (Model 2 in Table 4). ${ }^{11}$ The coefficient of the interaction variable is statistically indistinguishable from zero, suggesting that the proportion of Kurds living in the local population has no impact on respondents' level of disturbance by a Kurdish neighbour. ${ }^{12}$ Thus, we do not find evidence in the Turkish context for either of the group-level theories about how the relative size of the minority group might shape the majority group's prejudice.

\section{Conclusions}

In this article we sought to explore prejudicial attitudes of Turkish citizens using a population-based survey experiment. Our experimental treatments involved manipulations across two salient dimensions of Turkish politics - while the ethnicity stimuli focused on Kurdish language and geography, the religiosity stimuli focused on piety and religiously-motivated head covering of women. We have found that while the religiosity stimulus appears to be ineffective in creating significant differentials in prejudice, as measured by the level of disturbance by a hypothetical family moving in as a neighbour, the Kurdish ethnicity stimulus is effective. Among the non-Kurdish speaking respondents in our sample, older individuals, individuals with lower levels of education and who are dissatisfied with their own economic conditions appear to show greater levels of prejudice against Kurds.

The fact that our religiosity stimuli did not lead to meaningfully significant differences in prejudice across the experimental groups may be due to several factors. One factor is that most 
of the relevant research clearly shows that most Turks are quite religious to start with. Despite the ongoing tension between the secularist and Islamist groups in the country, most Turks report high levels of religious practice, and about $60 \%$ of Turkish women report covering their heads with some form of headscarf (Çarkoğlu, 2009). Our results suggest that major socio-political cleavages do not necessarily impact on intergroup attitudes. Second, the fact the conservative, Islamist AKP has been in power since 2002 and effectively resolved the headscarf-ban problem in universities and public institutions might also have eased the tension. Additionally, some respondents who perceived our experimental stimuli and measure of prejudice as too explicit may have chosen to report a level of disturbance that is lower than its actual value due to social desirability bias. Finally, emphasizing different lifestyles across the religious/secular dimension more forcefully (e.g., stricter forms of religious attire both for men and women, consuming alcohol) together with more unobtrusive measures of prejudice might result in different results.

Our findings on the individual-level correlates of prejudice against a Kurdish neighbour show that the factors that are emphasized in the literature (e.g., age, level of education, economic satisfaction) are at work in the Turkish context as well. From an optimistic perspective these findings could be taken as encouraging since they suggest that Turkish prejudice against Kurds does not have a sui generis nature. Beyond the individual-level factors, we do not find any impact from the proportion of Kurds living in the local population on levels of prejudice against them. We tend to take this result as tentative, however, because of challenges associated with testing the group-threat and intergroup contact hypotheses in the present context. More detailed estimates of the relative sizes of Kurdish population at the local levels should be constructed, as well as on the levels of segregation of Turkish and Kurdish populations at these localities. In 
addition, data that would allow us to assess the frequency and quality of contact between the two groups should be collected as well (Pettigrew, 1998).

A final note of caution concerns the timing of our fieldwork which took place at a time when the Turkish state's military engagement with the Kurdish separatist organization PKK (Partiya Karkerên Kurdistanê - Kurdistan Worker's Party) was at a low point and a civilian rapprochement between the AKP government and the Kurdish political movement was in process. At the time of writing of the article this civilian rapprochement had ended with rising PKK attacks and engagement with the Turkish security forces that resulted in numerous losses of life. A replication of our experiment in the current tense Turkish political environment would likely result in heightened prejudice against Kurdish ethnicity; thus our findings should be taken as a baseline level of prejudice measured in a period of relatively low salience and intensity of the Kurdish conflict in Turkey.

\section{Funding}

This work was supported by the Scientific and Technological Research Council of Turkey (TÜBİTAK) [grant number 112K157]. 


\section{Notes}

${ }^{1}$ Relevant studies on the social and political consequences of prejudice include Bar-Tal and Teichman (2009), Brader et al. (2008), Harell et al. (2014), Krupnikov and Piston (2015), Kuklinski et al. (1997), Terkildsen (1993).

${ }^{2}$ Another potential source of tension in Turkish society is based on sectarian differences, between the Hanefi Sunni majority and Shi-a Alevi minority (see Çarkoğlu and Bilgili, 2012). In this study we are interested in the potential reflections of a cleavage around religiosity, not along sectarian lines.

${ }^{3}$ The Kurds comprise a large ethnic group in Turkey with a concentration in the Eastern and Southeastern provinces of the country. Our survey data estimate the proportion of Kurds within the adult population of Turkey to be $15.4 \%$. Militarized conflict between the Turkish state and the Kurdish ethno-nationalist movement over the last three decades has challenged Turkish democracy. There is a significant literature on the Kurdish conflict in Turkey with a proliferation of recent contributions, e.g., Romano (2006), Marcus (2007), Tezcür (2010, 2016).

${ }^{4}$ The authors acknowledge the concern of endogeneity, yet argue that one of the indicators they employed to measure private contact, 'having a parent from the ethnic out-group', should be exogenous. Nevertheless, the concern still persists as the likelihood of reporting whether one has a parent from the ethnic out-group might be endogenous, and other indicators used for private contact (e.g., having a partner from the out-group) are clearly endogenous.

${ }^{5}$ The survey was fielded as part of the International Social Survey Program (ISSP) Family and Changing Gender Roles IV Module. The sampling procedure starts with the use of Turkish Statistical Institute's (TUIK) NUTS-2 regions. The target sample was distributed according to 
each region's share of urban and rural population in accordance with current records of the Address Based Population Registration System (ADNKS). Next, TUIK's block data were used with block size set at 400 residents. Twenty voters were targeted from each block and no substitution was used. Probability-proportionate-to-size (PPS) principle was used in distributing the blocks to NUTS-2 regions. Selection of individuals in households is done on the basis of reported target population of 18 years or older in each household according to a lottery method. If for any reason that individual could not respond to our questions in our first visit, then the same household is visited up to three times until a successful interview is conducted. Detailed information about the questionnaire and sampling methodology are available at http://www.gesis.org/en/issp/home/.

${ }^{6}$ A multinomial logistic regression of treatment assignment to respondent characteristics (age, gender, education, speaking Kurdish) affirms balance among treatment conditions (Wald $\left.\chi^{2}(12)=7.33, p<0.83\right)$.

${ }^{7}$ Different forms of women's head covering, some associated with Islamic conservatism and some not, have long existed in Turkey, and the issue has become contentious with the rise of political Islam (Çarkoğlu, 2009). There is no broad consensus in the terminology to describe different forms of head covering, however. For example, in conservative circles the Islamic head covering is typically referred to as başörtüsü while individuals in more secular circles might prefer to use the term türban. In our vignettes we used the term tesettürlü (literally 'being veiled or covered') which has a clearer signal of Islamic conservatism than alternative designations. ${ }^{8}$ One way to address the issue of social desirability bias is to use an unobtrusive measurement technique, such as a list experiment (Kuklinski et al., 1997), for the sensitive attitude or behavior. List experiments have been employed to study racial attitudes (Kuklinski et al., 1997), voter 
turnout (Holbrook and Krosnick, 2010) and vote buying (Çarkoğlu and Aytaç, 2015). In the present study we opted not to use a list experiment because we have manipulations in two dimensions, which would necessitate greater number of experimental groups.

${ }^{9}$ Sarıgil and Karakoç (2016) ask their respondents whether they would be disturbed or bothered by a neighbour having Turkish/Kurdish origin, eliciting yes or no answers. They report that about $81 \%$ of Turks and $95 \%$ of Kurds in their sample did not report disturbance when asked this way. Despite the differences in methodology and measurement, their results point to similarly low levels of prejudice in terms of neighbour preferences.

${ }^{10}$ About $15 \%$ of our respondents declared that they could speak Kurdish, and as speaking Kurdish is strongly and negatively associated with prejudice against a Kurdish family, we discarded these respondents from the subsequent analysis for the purpose of determining the drivers of such prejudice. The inclusion of these respondents in our analyses does not lead to a substantive change in the reported results.

${ }^{11}$ Since there have not been any ethnicity or mother tongue question in the Turkish official census since 1965 , we have to rely on estimates to determine the size of the Kurdish population in provinces and districts. While Kurds formed 7.6\% of the population in the country in 1965 (Devlet Istatistik Enstitüsü 1969), Mutlu (1996) conducted a province-level analysis and estimated the proportion of Kurds in Turkey to be $12.6 \%$ in 1990 . We are not aware of any published district-level estimates of the Kurdish population. In order to create the district-level estimates used in the present analysis, first we extrapolated from Mutlu's study to estimate the province-level population of Kurds in 2012. Next, for each district, we extracted the birthregistry information of individuals living in that district from Turkish Statistical Institute's Address-Based Population Registry System (ADNKS) to determine their province of 
registration. Finally we used the province-level estimates of Kurdish population and the distribution of province-level registries of individuals in districts to estimate the proportion of Kurds living in each district. In the model we use the natural logarithm of the estimated proportions.

${ }^{12}$ In Model 2 of Table 4 we used OLS regression with robust standard errors clustered by districts to facilitate the interpretation of results. Using a hierarchical liner model with random coefficients and intercepts leads to identical results. 


\section{References}

Aktürk, Şener (2015) Religion and Nationalism: Contradictions of Islamic Origins and Secular Nation-Building in Turkey, Algeria, and Pakistan. Social Science Quarterly 96(3): 778806.

Allport, Gordon W (1954) The Nature of Prejudice. Reading: Addison-Wesley.

Bar-Tal, Daniel, and Yona Teichman (2009) Stereotypes and Prejudice in Conflict:

Representations of Arabs in Israeli Jewish Society. New York: Cambridge University Press.

Bilali, Rezarta (2014) The Downsides of National Identification for Minority Groups in Intergroup Conflicts in Assimilationist Societies. British Journal of Social Psychology 53: 21-38.

Bishop, Bill (2008) The Big Sort: Why the Clustering of Like-minded America is Tearing Us Apart. Boston: Houghton Mifflin Harcourt.

Blalock, Hubert M. (1957) Percent Non-white and Discrimination in the South. American Sociological Review 22(6): 677-82.

Blalock, Hubert M. (1967) Toward a Theory of Minority-group Relations. New York: John Wiley and Sons.

Bobo, Lawrence, and Camille L. Zubrinsky (1996) Attitudes on Residential Integration: Perceived Status Differences, Mere In-group Preference, or Racial Prejudice? Social Forces 74(3): 883-909.

Bradburn, Norman, M., Seymour Sudman, Ed Blair, and Carol Stocking (1970) Question Threat and Response Bias. Public Opinion Quarterly 42(2): 221-34. 
Brader, Ted, Nicholas A. Valentino, and Elizabeth Suhay (2008) What Triggers Public Opposition to Immigration? Anxiety, Group Cues, and Immigration Threat. American Journal of Political Science 52(4): 959-78.

Burns, Peter, and James G. Gimpel (2000) Economic Insecurity, Prejudicial Stereotypes, and Public Opinion on Immigration Policy. Political Science Quarterly 115(2): 201-25.

Charles, Camille Z. (2003) The Dynamics of Racial Residential Segregation. Annual Review of Sociology 29: 167-207.

Coenders, Marcel, and Peer Scheepers (2003) The Effect of Education on Nationalism and Ethnic Exclusionism: An International Comparison. Political Psychology 24(2): 313-43.

Çarkoğlu, Ali (2009) Women's Choices of Head Cover in Turkey: An Empirical Assessment. Comparative Studies of South Asia, Africa and the Middle East 9(3): 450-61.

Çarkoğlu, Ali, and Nazlı Ç. Bilgili (2012) Alevis in Turkish Politics in Power and Powerlessness: Religious Minorities in the Middle East, A.N. Longva and A.S. Roald (eds.), 289-308, Leiden: Brill.

Çarkoğlu, Ali, and S. Erdem Aytaç (2015) Who Gets Targeted for Vote-Buying? Evidence from an Augmented List Experiment in Turkey. European Political Science Review 7(4): 547566.

Çelebi, Elif, Maykel Verkuyten, Talha Köse, and Mieke Maliepaard (2014) Out-group Trust and Conflict Understandings: The Perspective of Turks and Kurds in Turkey. International Journal of Intercultural Relations 40: 64-75.

Çelebi, Elif, Maykel Verkuyten, Natasa Smyrnioti (2016) Support for Kurdish Language Rights in Turkey: The Roles of Ethnic Group, Group Identifications, Contact, and Intergroup Perceptions. Ethnic and Racial Studies 39(6): 1034-1051. 
Devlet İstatistik Enstitüsü (1969) Genel Nüfus Sayımı: Nüfusun Sosyal ve Ekonomik Nitelikleri, 24.10.1965. Ankara: Devlet İstatistik Enstitüsü.

Dixon, Jeffrey C., and Michael S. Rosenbaum (2004) Nice to Know You? Testing Contact, Cultural, and Group Threat Theories of Anti-Black and Anti-Hispanic Stereotypes. Social Science Quarterly 85(2): 257-80.

Firebaugh, Glenn, and Kenneth E. Davis (1988) Trends in Anti-black Prejudice, 1972-1984. American Journal of Sociology 94(2): 251-72.

Harell, Allison, Stuart Soroka, and Kiera Ladner (2014) Public Opinion, Prejudice, and the Racialization of Welfare in Canada. Ethnic and Racial Studies 37(14): 2580-97.

Holbrook, Allyson L., and Jon A. Krosnick (2010) Social Desirability Bias in Voter Turnout Reports: Tests Using the Item Count Technique. Public Opinion Quarterly 74(1): 37-67.

Hood, M.V., and Irwin L. Morris (1997) ¿Amigo o Enemigo? Context, Attitudes, and Anglo Public Opinion toward Immigration. Social Science Quarterly 78(2): 309-23.

Krupnikov, Yanna, and Spencer Piston (2015) Racial Prejudice, Partisanship, and White Turnout in Elections with Black Candidates. Political Behavior 37(2): 397-418.

Krysan, Maria (2000) Prejudice, Politics, and Public Opinion: Understanding the Sources of Racial Policy Attitudes. Annual Review of Sociology 26: 135-68.

Kuklinski, James H., Paul M. Sniderman, Kathleen Knight, Thomas Piazza, Philip E. Tetlock, Gordon R. Lawrence, and Barbara Mellers (1997) Racial Prejudice and Attitudes toward Affirmative Action. American Journal of Political Science 41(2): 402-19.

Marcus, Aliza (2007) Blood and Belief: The PKK and the Kurdish Fight for Independence. New York: New York University Press. 
Mardin, Şerif (1973) Center-Periphery Relations: A Key to Turkish Politics? Daedalus 102(1): $169-90$.

Massey, Douglas S., and Nancy A. Denton (1988) The Dimensions of Residential Segregation. Social Forces 67(2): 281-315.

Mutlu, Servet. (1996) Ethnic Kurds in Turkey: A Demographic Study. International Journal of Middle East Studies 28(4): 517-41.

Mutz, Diana C. (2011) Population-based Survey Experiments. Princeton: Princeton University Press.

Pettigrew, Thomas F. (1980) Prejudice. In Stephan Themstrom, Ann Orlov, and Oscar Handling (Eds.), The Harvard Encyclopedia of American Ethnic Groups 820-29. Cambridge: The Belknap Press.

Pettigrew, Thomas F. (1998) Intergroup Contact Theory. Annual Review of Psychology 49(1): $65-85$.

Pettigrew, Thomas F., and Linda R. Tropp (2006) A Meta-analytic Test of Intergroup Contact Theory. Journal of Personality and Social Psychology 90(5): 751-83.

Quillian, Lincoln (1995) Prejudice as a Response to Perceived Group Threat: Population Composition and Anti-immigrant and Racial Prejudice in Europe. American Sociological Review 60(4): 586-611.

Romano, David (2006) The Kurdish Nationalist Movement: Opportunity, Mobilization, and Identity. New York: Cambridge University Press.

Saraçoğlu, Cenk (2009) Exclusive Recognition: The Novel Dynamics of the Question of Ethnicity and Nationalism in Turkey. Ethnic and Racial Studies 32(4): 640-58. 
Sarıgil, Zeki, and Ekrem Karakoç (2016) Inter-ethnic (In)tolerance between Turks and Kurds: Implications for Turkish Democratisation. South European Society and Politics, DOI:10.1080/13608746.2016.1164846.

Schuman, Howard (1997) Racial Attitudes in America: Trends and Interpretations. Cambridge: Harvard University Press.

Taylor, Marylee C. (1998) How White Attitudes Vary with the Racial Composition of Local Populations: Numbers Count. American Sociological Review 63(4): 512-35.

Terkildsen, Nayda (1993) When White Voters Evaluate Black Candidates: The Processing Implications of Candidate Skin Color, Prejudice, and Self-monitoring. American Journal of Political Science 37(4): 1032-53.

Tezcür, Güneş Murat (2010) When Democratization Radicalizes? The Kurdish Nationalist Movement in Turkey. Journal of Peace Research 47(6): 775-89.

Tezcür, Güneş Murat (2016) Ordinary People, Extraordinary Risks: Participation in an Ethnic Rebellion. American Political Science Review 110(2): 247-264.

Wagner, Ulrich, Rolf van Dick, Thomas F. Pettigrew, and Oliver Christ (2003) Ethnic Prejudice in East and West Germany: The Explanatory Power of Intergroup Contact. Group Processes \& Intergroup Relations 6(1): 22-36. 


\section{Author biographies}

S. Erdem Aytaç is an assistant professor in the Department of International Relations at Koç University. He received his PhD from Yale University in 2014 and his research focuses on comparative political behaviour and electoral politics.

Ali Çarkoğlu is a professor in the Department of International Relations at Koç University. He received his PhD from the State University of New York-Binghamton in 1994, and previously taught at Boğaziçi University and Sabancı University in Istanbul. His areas of research interest include voting behaviour, public opinion, and party politics in Turkey.

\section{Tables}

Table 1. Descriptive Statistics of the Sample

\begin{tabular}{lc}
\hline Male $(\%)$ & 47.5 \\
Median age & 38 \\
Primary school or below (\%) & 49.3 \\
Kurdish-speaking (\%) & 15.4 \\
Praying more than once a week (\%) & 46.8 \\
$N$ & 1,620 \\
\hline
\end{tabular}


Table 2. The Experimental Setup

\begin{tabular}{|l|l|l|}
\hline \multicolumn{2}{|l|}{ Religiosity Dimension } \\
\hline Ethnicity Dimension & Secular & Religious \\
\hline Kurdish & Kurdish-secular (Group 1) & Kurdish-religious (Group 2) \\
\hline Turkish & Turkish-secular (Group 3) & Turkish-religious (Group 4) \\
\hline
\end{tabular}


Table 3. Regression analyses of average treatment effects (base category is Turkish-Secular treatment)

\begin{tabular}{llclc}
\hline \multirow{2}{*}{$\begin{array}{l}\text { DV: Level of } \\
\text { disturbance }\end{array}$} & \multicolumn{2}{c}{$\begin{array}{c}\text { Model without } \\
\text { Covariates }\end{array}$} & \multicolumn{2}{c}{ Model with } \\
& Coef. & $S E$ & Coef. & $S E$ \\
\hline Kurdish-Secular & $0.665^{* * *}$ & $(0.187)$ & $0.656^{* * *}$ & $(0.189)$ \\
Kurdish-Religious & $0.599^{* * *}$ & $(0.186)$ & $0.627^{* * *}$ & $(0.187)$ \\
Turkish-Religious & 0.040 & $(0.163)$ & 0.028 & $(0.163)$ \\
Male & & & 0.111 & $(0.140)$ \\
Age & & & -0.005 & $(0.005)$ \\
Beyond Primary Educ. & & & 0.091 & $(0.147)$ \\
Kurdish-Speaking & & & $-0.838^{* * *}$ & $(0.177)$ \\
Religious & & & 0.198 & $(0.144)$ \\
Constant & $1.527^{* * *}$ & $(0.118)$ & $1.680^{* * *}$ & $(0.261)$ \\
\hline Observations & 1,595 & & 1,563 & \\
$R^{2}$ & 0.013 & & 0.028 & \\
\hline
\end{tabular}

Robust standard errors in parentheses. ${ }^{*} p<0.10,{ }^{* *} p<0.05,{ }^{* * *} p<0.01$

Note: 'Beyond Primary Educ.' is a dummy variable taking the value of 1 for respondents with education beyond the primary level and 0 for others. 'Religious' is a dummy variable taking the value of 1 for respondents who reported praying (namaz) more than once a week in the last year. 
Table 4. Regression analyses of average treatment effects of (pooled) Kurdish-ethnicity treatment, excluding Kurdish speakers (base category is (pooled) Turkish-ethnicity treatment)

\begin{tabular}{llrlc}
\hline DV: Level of & \multicolumn{2}{c}{ Model (1) } & \multicolumn{2}{c}{ Model (2) } \\
disturbance & Coef. & SE & Coef. & SE \\
\hline Kurdish Treatment & 1.016 & $(0.698)$ & 1.156 & $(0.824)$ \\
Male & -0.052 & $(0.190)$ & -0.089 & $(0.188)$ \\
$\quad$ Interaction with treatment & 0.380 & $(0.314)$ & 0.342 & $(0.314)$ \\
Age & $-0.017^{* *}$ & $(0.007)$ & $-0.018^{* * *}$ & $(0.007)$ \\
$\quad$ Interaction with treatment & $0.019^{*}$ & $(0.011)$ & $0.019^{*}$ & $(0.011)$ \\
Beyond Primary Educ. & 0.201 & $(0.194)$ & 0.178 & $(0.193)$ \\
$\quad$ Interaction with treatment & $-0.624^{*}$ & $(0.332)$ & $-0.577^{*}$ & $(0.330)$ \\
Position in Society & 0.081 & $(0.049)$ & 0.076 & $(0.049)$ \\
$\quad$ Interaction with treatment & -0.027 & $(0.085)$ & -0.015 & $(0.085)$ \\
Economic Satisfaction & -0.031 & $(0.038)$ & -0.031 & $(0.038)$ \\
$\quad$ Interaction with treatment & $-0.171^{* *}$ & $(0.067)$ & $-0.172^{* *}$ & $(0.066)$ \\
Religiosity & 0.247 & $(0.206)$ & 0.232 & $(0.205)$ \\
$\quad$ Interaction with treatment & 0.142 & $(0.334)$ & 0.154 & $(0.332)$ \\
Kurdish Population & & & $-0.377^{* * *}$ & $(0.126)$ \\
$\quad$ Interaction with treatment & & & 0.091 & $(0.185)$ \\
Constant & $1.883^{* * *}$ & $(0.382)$ & 1.028 & $(0.473)$ \\
\hline Observations & 1,300 & & 1,300 & \\
R2 & 0.049 & & 0.059 & \\
\hline
\end{tabular}

Robust standard errors in parentheses in Model 1. Robust standard errors clustered by districts in parentheses in Model 2. ${ }^{*} p<0.10,{ }^{* *} p<0.05,{ }^{* * *} p<0.01$.

Note: 'Beyond Primary Educ.' is a dummy variable taking the value of 1 for respondents with education beyond the primary level and 0 for others. 'Religious' is a dummy variable taking the value of 1 for respondents who reported praying (namaz) more than once a week in the last year. 
Figures

Figure 1. Mean levels of disturbance across experimental groups

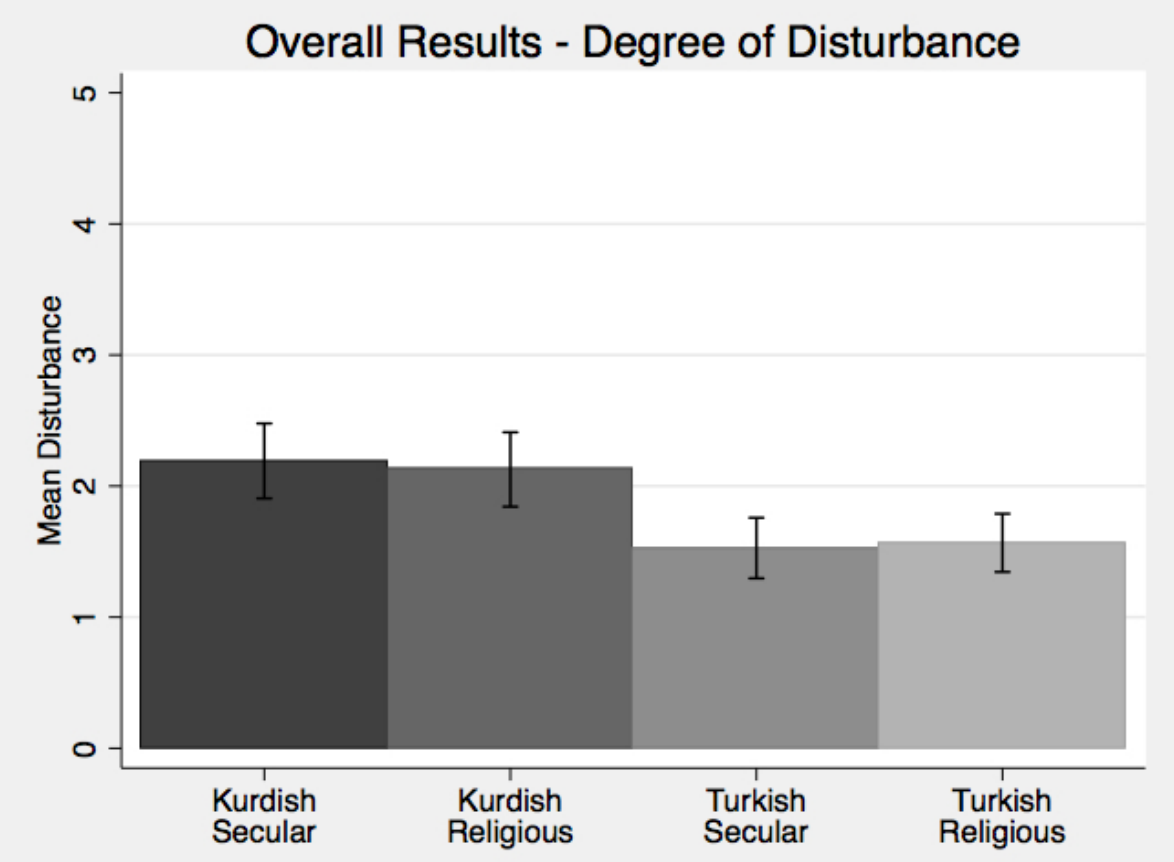

Note: Vertical lines display $95 \%$ confidence intervals around the group means. 
Figure 2. Mean levels of disturbance across experimental groups - the impact of education

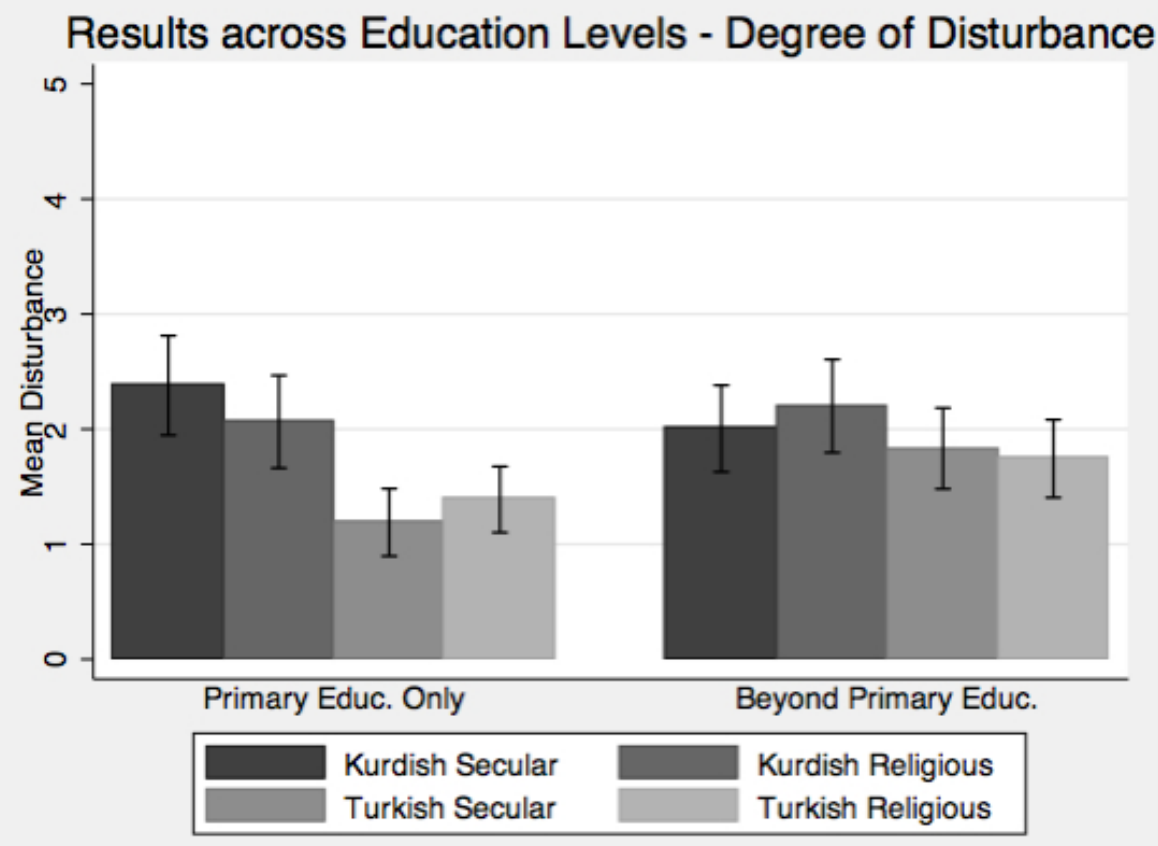

Note: Vertical lines display 95\% confidence intervals around the group means. 
Figure 3. Mean levels of disturbance across experimental groups - the impact of economic satisfaction

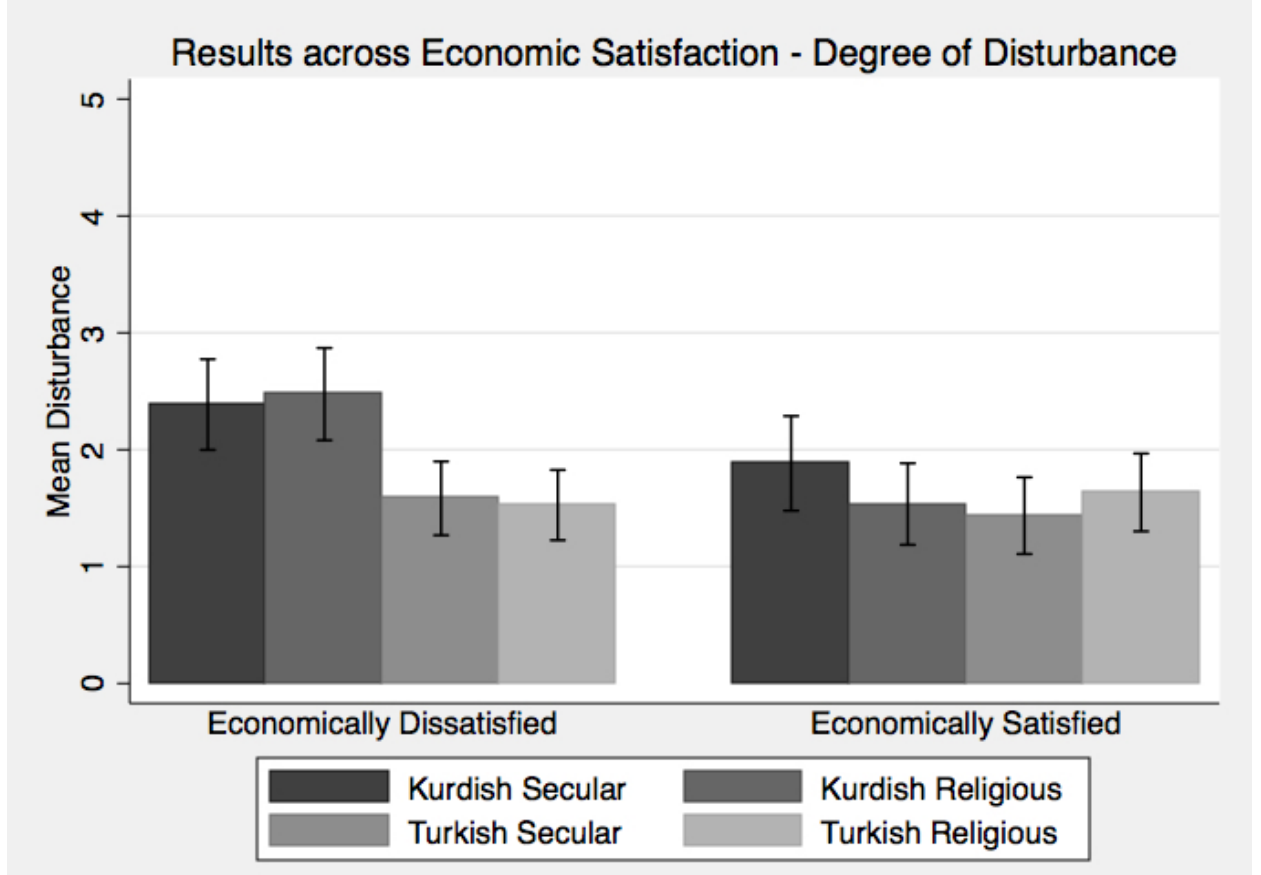

Note: Vertical lines display $95 \%$ confidence intervals around the group means. 